\title{
Dexamethasone Treatment Attenuates Pulmonary Injury in Piglet Meconium Aspiration
}

\author{
RIIKKA HOLOPAINEN, JUKKA LAINE, LAURI HALKOLA, HEIKKI AHO, AND PEKKA KÄÄPÄ \\ Cardiorespiratory Research Unit [R.H., L.H., P.K.], Department of Pathology [J.L., H.A.], and \\ Department of Pediatrics [P.K.], University of Turku, 20520 Turku, Finland
}

\begin{abstract}
ABST
To investigate the pulmonary effects of steroid treatment in
neonates with meconium aspiration, 2510 - to 12 -d-old piglets
were studied for $6 \mathrm{~h}$ after an intratracheal bolus of human
meconium. Dexamethasone $(0.5 \mathrm{mg} / \mathrm{kg})$ was given in two treat-
ment schedules, either $1 \mathrm{~h}$ before $(n=6)$ or $1 \mathrm{~h}$ after meconium
instillation $(n=8)$. Eight piglets served as controls. Three
additional piglets were given dexamethasone without meconium
instillation. Pulmonary hemodynamics and oxygenation were
followed, and lung tissue samples investigated for signs of
inflammation and ultrastructural injury, including apoptosis. Pul-
monary artery pressure and vascular resistance increased after
meconium instillation, but this rise was significantly prevented
after prophylactic dexamethasone. This treatment also improved
the acutely deteriorated oxygenation of the piglets after meco-
nium insufflation. Prophylactic, but not early, dexamethasone
treatment further protected the lungs from the ultrastructural
changes caused by meconium instillation. Additionally, the in-
\end{abstract}
ABSTRACT

Perinatal aspiration of meconium frequently results in severe respiratory failure with ventilation-perfusion mismatching in the lungs, hypoxemia, and increase in pulmonary vascular resistance associated with high morbidity and mortality among term infants (1). The pathophysiology of the meconium aspiration syndrome is complex, but inflammation with accumulation of polymorphonuclear leukocytes in the pulmonary tissue has been identified as a central event in the development of acute tissue damage $(2,3)$. This inflammatory reaction is associated with increased pulmonary vascular permeability leading to proteinaceous exudation into the alveolar spaces and inactivation of the pulmonary surfactant, and may together with direct toxic effects of meconium on the alveolocapillary membrane significantly contribute to the lung injury process $(1,3)$.

Glucocorticoids possess a potent anti-inflammatory activity by modulating the action of inflammatory mediators and reducing the activation and recruitment of leukocytes in the lungs

Received July 7 1999; Accepted January 5, 2000.

Correspondence: Riikka Holopainen, M.D., Cardiorespiratory Research Unit, University of Turku, FIN-20520 Turku, Finland.

Supported by The Finnish Heart Association, the Sigrid Juselius Foundation, and the Finnish Cultural Foundation. crease of apoptotic epithelial cell deaths was significantly prevented by both dexamethasone treatments. These results show that prophylactic dexamethasone treatment significantly attenuates the early pulmonary hemodynamic deterioration and structural lung damage caused by meconium aspiration. Further studies on the apoptosis-inhibiting effect of dexamethasone administration in neonatal lungs exposed to heavy meconium are warranted. (Pediatr Res 49: 162-168, 2001)
Abbreviations:
$\mathrm{Fio}_{2}$, fraction of inspired oxygen
MABP, mean arterial blood pressure
MAS, meconium aspiration syndrome
MPAP, mean pulmonary artery pressure
PLA $_{2}$, phospholipase $\mathrm{A}_{2}$
PVR, pulmonary vascular resistance
SVR, systemic vascular resistance

(4). Steroids have been used with variable success to prevent and treat acute and chronic lung injury in immature newborn infants during the neonatal period $(5,6)$. Further, inflammatory and injurious changes from hyperoxia and barotrauma in mature neonatal lungs may be significantly ameliorated by prophylactic treatment with dexamethasone (7). In meconium aspiration, however, the results from the use of steroid therapy have been controversial $(8,9)$, and glucocorticoids have not been recommended for the treatment of infants with meconium aspiration. Nevertheless, a recent study in our laboratory suggested that prophylactic high-dose methylprednisolone administration has beneficial effects on the course of meconium aspiration-induced lung injury in pigs (10).

The aim of this work was to study the possible protective and therapeutic effects of dexamethasone on pulmonary hemodynamics and oxygenation in severe neonatal meconium aspiration and to further investigate the potentially modifying features of this treatment on the meconium aspiration-induced pulmonary tissue inflammation and phospholipase $\mathrm{A}_{2}$ activity, as well as apoptosis of alveolar cells. Newborn piglet was chosen as the experimental animal because of its similar lung morphology to that in human (11). 


\section{METHODS}

Animals. Twenty-five 10- to 12-d-old piglets (mean weight $4.6 \mathrm{~kg}$, range $3.5-5.2 \mathrm{~kg}$ ) were anesthetized and catheterized, as described earlier (12). Briefly, animals were premedicated with ketamine hydrochloride $(40 \mathrm{mg} / \mathrm{kg})$ i.m. and diazepam (2 $\mathrm{mg} / \mathrm{kg}$ ) i.m. and placed in supine position. They were then intubated and connected to a volume-controlled ventilator. Mechanical ventilation was started with room air, ventilatory rate being 28 breaths $/ \mathrm{min}$, end expiratory pressure $2-3 \mathrm{~cm}$ $\mathrm{H}_{2} \mathrm{O}$, and tidal volume $16-20 \mathrm{~mL} / \mathrm{kg}$. Anesthesia was maintained by continuous i.v. infusion of ketamine hydrochloride $\left(10 \mathrm{mg} \cdot \mathrm{kg}^{-1} \cdot \mathrm{h}^{-1}\right)$. Paralysis was induced with pancuronium bromide $(0.1 \mathrm{mg} / \mathrm{kg})$ i.v. and maintained with continuous infusion $\left(0.25 \mathrm{mg} \cdot \mathrm{kg}^{-1} \cdot \mathrm{h}^{-1}\right)$. Thrombus formation along the catheters was prevented by heparinizing all the infusions solutions $(8 \mathrm{IU} / \mathrm{mL})$.

The experiments were approved by the Committee of Animal Care in Research of the University of Turku. Animals were cared for in accordance with procedures outlined in the Guide for the Care and Use of Laboratory Animals (National Institutes of Health Publication No. 85-23).

Measurements. A 5F Swan-Ganz thermodilution catheter (Baxter Corp., Irvine, CA, U.S.A.) was inserted via the right external jugular vein and placed under pressure monitoring into the pulmonary artery for measurement of MPAP, pulmonary wedge pressure, and central venous pressure at end-expiration, as well as cardiac output. Further, to monitor systemic hemodynamics and to collect blood samples, a small polyethylene catheter was placed in the abdominal aorta via the right femoral artery. Mean airway pressure was monitored from the proximal end of the endotracheal tube. Pressures were measured using Baxter Uniflow transducers (Model 43-600, Bentley Laboratories, Uden, Holland) and a hemodynamic and respiratory computer system (Olli 530, Kone Oy, Helsinki, Finland), and recorded on an eight-channel recorder (Mingograf 82, Siemens-Elema, Solna, Sweden). Surface ECG was recorded for heart rate. PVR was calculated as the difference between the MPAP and pulmonary wedge pressure divided by cardiac output, and the SVR as the difference between the MABP and central venous pressure divided by cardiac output.

Blood $\mathrm{pH}, \mathrm{PcO}_{2}, \mathrm{Po}_{2}$ and oxygen saturation were measured by an automatic blood gas analyzer (Radiometer ABL 50, Copenhagen, Denmark) immediately after obtaining the samples from the aorta and pulmonary artery and correction for body temperature. $\mathrm{Hb}$ was measured by an electronic analyzer (Coulter Stdr, Luton, England). The intrapulmonary shunt fraction was calculated from the standard shunt equations on $100 \%$ oxygen.

Experimental protocol. After $1 \mathrm{~h}$ of stabilization and subsequent baseline measurements, 22 piglets received a bolus (3 $\mathrm{mL} / \mathrm{kg}$ ) of a $65 \mathrm{mg} / \mathrm{mL}$ mixture of human meconium via the endotracheal tube. The meconium was obtained from the first stools of several healthy term infants. It was then pooled, lyophilized, and irradiated for sterility, and before the experiment diluted with sterile saline. We have previously shown that intratracheal instillation of this amount of meconium induces a progressive pulmonary hypertension in neonatal piglets (12).
Dexamethasone (Decadron ${ }^{\circledR}, 4 \mathrm{mg} / \mathrm{mL}$, MSD, Amsterdam, The Netherlands) was infused as a single i.v. bolus $(0.5 \mathrm{mg} / \mathrm{kg})$ in six piglets $1 \mathrm{~h}$ before (Dexa-1) and in eight piglets $1 \mathrm{~h}$ after meconium instillation (Dexa-2). Eight untreated piglets served as controls. Additionally, three piglets without instillation of meconium into the airways were studied and were given the same amount $(0.5 \mathrm{mg} / \mathrm{kg})$ of dexamethasone i.v., simultaneously with the baseline measurements (Dexa-3). The hemodynamic changes were registered and blood gas samples taken at baseline and serially for $6 \mathrm{~h}$ after meconium instillation. To avoid hypoxemia, the piglets received supplemental oxygen to maintain arterial $\mathrm{Po}_{2}$ above $8 \mathrm{kPa}(60 \mathrm{~mm} \mathrm{Hg})$. The arterial $\mathrm{PcO}_{2}$ was maintained below $5 \mathrm{kPa}(38 \mathrm{~mm} \mathrm{Hg})$ by adjusting the frequency of the ventilator. Two of the piglets in the control group died due to respiratory failure before the completion of the experiment and were excluded from further analysis. At the end of the experiment the animals were killed with an overdose of potassium chloride.

Histologic examinations. For histologic analysis of the lungs, a $2 \times 2 \times 2 \mathrm{~cm}$ piece of pulmonary tissue from the right lower lobe was fixed in buffered formalin. The tissue samples were dehydrated, cleared, and embedded to paraffin according to a routine process. Five-micrometer sections were stained with hematoxylin and eosin for light microscopic analysis. To determine the extension and severity of the lung tissue injury, the histologic samples were assessed by a pathologist blinded to the grouping of the piglets. A score from 0 to 4 was assigned for three different characteristics: 1) extent of leukocyte infiltration, 2) amount of intra-alveolar leukocytes, and 3) amount of exudative debris, including fibrin, edema fluid, and meconium. The calculated total injury score means the sum of these scores.

Electron microscopy. For ultrastructural analysis of the lungs, small pieces $\left(1 \mathrm{~mm}^{3}\right)$ of pulmonary tissue were taken from the lateral diaphragmatic edge of the right lower lobe. The samples were fixed in 3.0\% phosphate-buffered glutaraldehyde, postfixed in $1 \%$ osmium tetroxide and embedded in Epon 812. Sections $1 \mu \mathrm{m}$ in thickness were cut and stained with toluidine blue. The slides were then examined under the light microscope and selected areas were processed for ultrathin sections, which were contrasted by uranyl acetate and lead citrate. The grids were studied in a Jeol JEM 1200 EX microscope (Tokyo, Japan).

Phospholipase $A_{2}$ activity. Because the catalytic activity of phospholipase $\mathrm{A}_{2}$ may be increased in inflamed tissues (13), this enzyme activity in lung tissue homogenates was measured as earlier described $(13,14)$.

In situ detection of apoptotic cells. In situ detection of apoptotic cells in paraffin sections of the lung tissue (right lower lobe) was performed by in situ nick-end labeling method (TUNEL), as reported earlier (13). Piglet lymphocytes undergoing apoptosis in the lymph nodes adjacent to lung tissue served as a positive control. Apoptotic cells were counted in lung sections. A distinct intensively dark color reaction within lung tissue cells was regarded to represent apoptotic DNA fragmentation. The results are expressed as the number of positive cells per square millimeter of tissue section area in 20 microscopic fields of a $10 \times$ magnifying objective lens at each 
time point. The method is well established in detection of apoptotic cellular changes and was validated by simultaneous electrophoretic DNA analysis in pancreatic tissue (13).

Data analysis. Physiologic data were analyzed using twoway ANOVA with repeated measures to compare the groups at each time point. The Mann-Whitney rank sum test was used to analyze the possible differences between the groups. For histologic and biochemical results, ANOVA was used to compare the groups. If the overall ANOVA was significant, posthoc comparisons between the groups were made using the StudentNewman-Keuls test. A level of $p<0.05$ was considered statistically significant. The results are expressed as mean $( \pm \mathrm{SEM})$

\section{RESULTS}

Physiologic changes. As previously reported (12), pulmonary artery pressure and vascular resistance increased progressively after instillation of meconium (Fig. 1, Table 1). Dexamethasone treatment did not have any effects on pulmonary hemodynamics at baseline, but prophylactic (unlike early) dexamethasone significantly prevented the meconium-induced rise in the pulmonary pressure, and vascular resistance (Fig. 1, Table 1). On the other hand, MABP increased after early dexamethasone treatment, but SVR was not affected by the dexamethasone administration (Table 1).
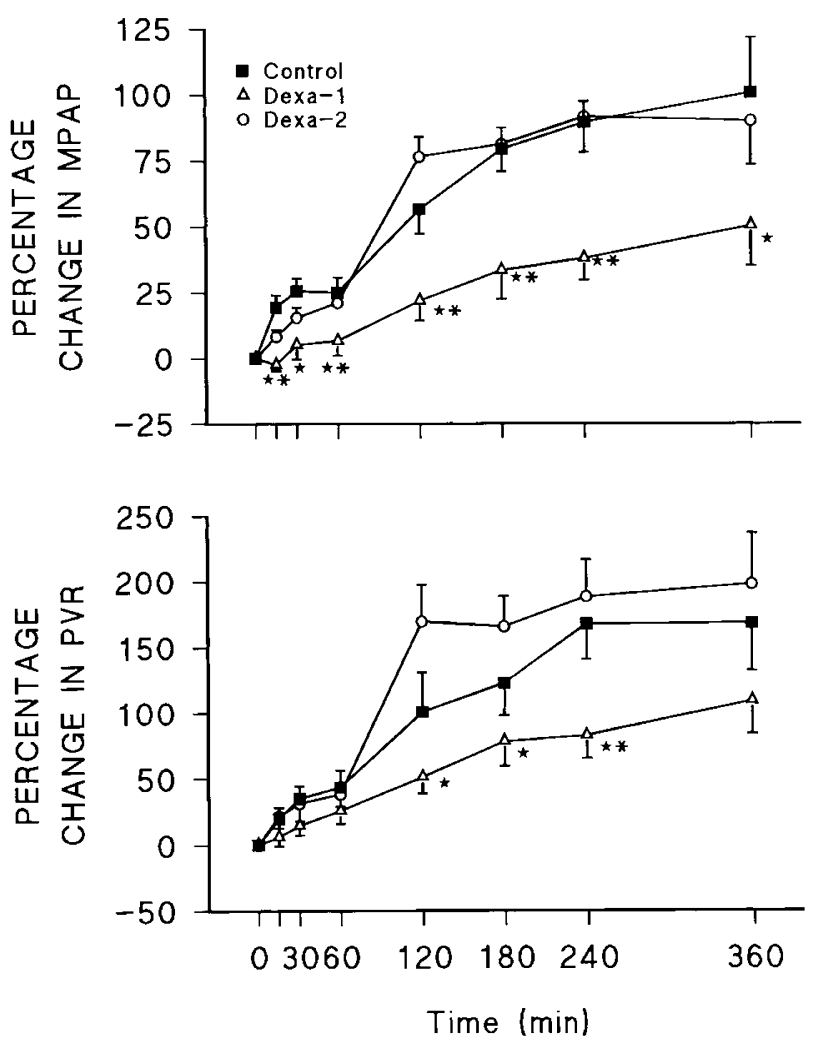

Figure 1. The percentage change in the MPAP (upper panel) and PVR (lower panel) in 20 newborn piglets at baseline (0) and during $6 \mathrm{~h}$ after intratracheal instillation of meconium. Fourteen piglets were treated with dexamethasone given as a single i.v. dose $(0.5 \mathrm{mg} / \mathrm{kg})$ in two treatment schedules, either $1 \mathrm{~h}$ before (Dexa-1, $n=6$ ) or $1 \mathrm{~h}$ after meconium instillation (Dexa-2, $n=8$ ). Six nontreated piglets served as controls. Mean (SEM). ${ }^{*} p<0.05$ vs controls. ${ }^{* *} p$ $<0.05$ vs Dexa-2.
Oxygenation of the piglets, presented as the arterial $\mathrm{Po}_{2} /$ $\mathrm{FiO}_{2}$-ratio, deteriorated initially in all study groups after meconium instillation, but thereafter both regimens of dexamethasone tended to improve oxygenation (Fig. 2, upper panel). In the piglets with prophylactic dexamethasone administration, the arterial $\mathrm{Po}_{2} / \mathrm{Fio}_{2}$ ratio was significantly higher than in controls during the early period after meconium instillation (Table 2). The intrapulmonary shunt fraction increased acutely in all study groups after meconium administration, but the increase seemed to be attenuated in Dexa-1 group (Fig. 2, lower panel; Table 2). Subsequently, the shunt fraction decreased toward baseline in all study groups (Fig. 2, lower panel; Table 2). There were no significant differences in $\mathrm{pH}$ or arterial $\mathrm{PcO}_{2}$ between the study groups (data not shown).

Dexamethasone in ventilated piglets without meconium insult did not have any effect on pulmonary or systemic hemodynamics or oxygenation (data not shown).

Histologic findings. In the lungs instilled with meconium, patchy areas of severe acute inflammation were found. The alveoli were partly atelectatic and contained varying amounts of leukocytes, fibrin, and also occasional epithelial cells of the instilled meconium. Bronchi contained leukocytes, cell debris, and epithelial cells of meconium. No pulmonary hemorrhages or necrosis of pulmonary parenchyma were observed. The basic pulmonary reaction was similar in the Dexa-1 and Dexa-2 groups compared with controls. However, in contrast to Dexa-2 group, prophylactic dexamethasone treatment tended to decrease the severity of the pulmonary inflammatory changes. Consequently, the total injury score was at a borderline $(p=0.058)$ lower in Dexa-1 group than in the controls (Table 3). Dexamethasone administration did not affect the ventilated lungs without instilled meconium in the Dexa-3 group.

Electron microscopic findings. In the meconium-instilled lungs, alveolar walls showed slight reversible changes with intracellular edema and autophagocytosis, as described earlier (15). Fibrin and meconium were present in alveolar spaces in all the insufflated lungs. The alveolar walls in the Dexa-1 group were normal in most places (Fig. 3), but were partly detached with swollen endoplasmic reticulum in the Dexa-2 group (Fig. 4). Dexamethasone administration without meconium insult did not affect the normal lung ultrastructure in the Dexa-3 group.

Apoptosis. Data from our laboratory have previously shown that meconium instillation significantly increases the number of pulmonary apoptotic cells, mainly in the alveolar epithelium (15). In the present study, the number of apoptotic cells (Fig. 5) was significantly lower after both dexamethasone treatments (Dexa-1, $p=0.016$; Dexa-2, $p=0.014$ ) than in the nontreatment group (Fig. 6).

Inflammatory parameters. The lung left lower lobe wet/dry weight ratios were similar in all study groups (Table 3.). The lung tissue $\mathrm{PLA}_{2}$ activity in the control and dexamethasonetreated lungs were also similar (Table 3 ). No correlation between the tissue PLA $_{2}$ activity and injury score was found in any of the groups. Dexamethasone treatments prevented the meconium instillation-induced fall in the amount of blood leukocytes, and resulted in a marked increase in their number 
Table 1. Hemodynamic data during $6 \mathrm{~h}$ after intratracheal instillation of meconium in control $(N=6)$, dexamethasone-pretreated (Dexa-1, $N=6$ ), and dexamethasone treated (Dexa-2, $N=8$ ) neonatal piglets

\begin{tabular}{|c|c|c|c|c|c|c|c|c|}
\hline & \multicolumn{8}{|c|}{ Time (min) } \\
\hline & 0 & 15 & 30 & 60 & 120 & 180 & 240 & 360 \\
\hline \multicolumn{9}{|c|}{ MPAP (mm Hg) } \\
\hline Control & $13.0(2.9)$ & $15.3(2.3)$ & $16.2(2.7)$ & $16.0(2.1)$ & $20.0(2.8)$ & $23.0(3.4)$ & $24.3(3.8)$ & $25.8(7.4)$ \\
\hline Dexa-1 & $14.1(1.6)$ & $13.8(1.9)$ & $14.8(2.2)$ & $15.0(1.7)$ & $17.1(2.7) \dagger$ & $18.8(4.0) \dagger$ & $19.5(3.4)^{* \dagger}$ & $21.0(4.7)$ \\
\hline Dexa-2 & $13.8(1.0)$ & $15.0(1.2)$ & $16.0(1.5)$ & $16.7(0.8)$ & $24.3(2.1)^{*}$ & $25.0(3.0)$ & $26.3(4.0)$ & $26.1(5.5)$ \\
\hline \multicolumn{9}{|c|}{ PVR (mm Hg/L/min) } \\
\hline Control & $11.5(3.8)$ & $13.9(5.2)$ & $15.6(6.0)$ & $16.2(5.5)$ & $21.4(4.8)$ & $24.1(4.5)$ & $29.5(7.4)$ & $29.1(6.7)$ \\
\hline Dexa-1 & $10.4(2.9)$ & $11.0(3.5)$ & $11.9(4.0)$ & $12.7(3.2)$ & $15.5(5.5) \dagger$ & $18.1(6.0)$ & $18.5(5.9) \dagger$ & $20.7(5.3)^{*}$ \\
\hline Dexa-2 & $9.7(2.4)$ & $11.5(2.9)$ & $12.3(3.1)$ & $13.0(2.3)$ & $25.5(7.8)$ & $25.1(6.2)$ & $27.0(6.9)$ & $27.4(8.4)$ \\
\hline \multicolumn{9}{|c|}{ MABP (mm Hg) } \\
\hline Control & $67.1(17.8)$ & $66.5(12.1)$ & $66.1(11.2)$ & $69.5(9.1)$ & $71.3(9.5)$ & $76.3(10.5)$ & $75.8(8.9)$ & $71.5(13.1)$ \\
\hline Dexa-1 & $65.6(4.9)$ & $67.3(7.5)$ & $70.3(7.5)$ & $75.3(10.1)$ & $80.6(8.7)$ & $74.0(6.1) \dagger$ & $74.6(8.5) \dagger$ & $77.8(8.8)$ \\
\hline Dexa-2 & $74.0(13.7)$ & $75.5(14.6)$ & $78.8(14.7)$ & $81.8(14.4)$ & $90.6(15.5)^{*}$ & $88.3(14.1)$ & $94.0(15.3)^{*}$ & $89.5(15.4)^{*}$ \\
\hline \multicolumn{9}{|c|}{$\operatorname{SVR}(\mathrm{mm} \mathrm{Hg} / \mathrm{L} / \mathrm{min})$} \\
\hline Control & $59.9(17.4)$ & $62.5(20.2)$ & $65.8(25.1)$ & $72.7(23.5)$ & $84.1(20.5)$ & $90.4(16.7)$ & $98.2(20.9)$ & $90.4(24.2)$ \\
\hline Dexa-1 & $56.5(14.7)$ & $64.5(16.1)$ & $68.6(21.8)$ & $77.9(21.4)$ & $85.3(20.9)$ & $82.7(15.4)$ & $80.4(14.5)$ & $87.5(14.6)$ \\
\hline Dexa-2 & $64.0(15.3)$ & $68.4(22.2)$ & $69.3(18.0)$ & $73.7(16.8)$ & $108.9(24.2)$ & $104.2(24.0)$ & $111.2(25.0)$ & $108.1(25.2)$ \\
\hline
\end{tabular}

Results are expressed as the mean (SD).

$* p<0.05$ vs control.

$\dagger p<0.05$ vs Dexa-2.

from $3 \mathrm{~h}$ on, especially after prophylactic dexamethasone (Fig. 7).

\section{DISCUSSION}

The results of this experimental study indicate that dexamethasone treatment, especially when given prophylactically, attenuates the meconium aspiration-induced hypertensive response and inflammatory injury in 10- to 12-d-old piglet lungs, still in the process of postnatal adaptation (11). This finding corroborates similar experimental results from prophylactic administration of dexamethasone in hyperoxic hyperventilated neonatal lungs (7) and high-dose methylprednisolone in meconium-exposed juvenile lungs (10). In addition to pretreatment, early high-dose glucocorticoid treatment of lung injury may also prevent further pulmonary damage, whereas steroids given at the time of well-established injury have only limited or no positive effects (16-18). Accordingly, controlled clinical trials of pre- and postnatal dexamethasone administration have shown significant improvements in the course of respiratory distress syndrome in premature infants $(5,6)$. In meconium aspiration syndrome, based on previous negative results of low-dose hydrocortisone therapy $(8,9)$, steroid treatment is presently not recommended. Our present and earlier data (10), however, suggest that studies on the clinical significance of dexamethasone treatment in term or post-term infants exposed to heavy meconium may be warranted.

Development of pulmonary hypertension often complicates the symptoms of infants with meconium aspiration syndrome. This hypertensive reaction, thought to result from meconiuminduced release of vasoactive mediators and altered pulmonary vasoreactivity $(1,19)$, is associated with microvascular endothelial changes in the meconium-exposed lungs already during the first hours after the insult (2). Corticosteroids have been demonstrated to modulate pulmonary vasomotor activity in hypertensive lung injuries by influencing the release and action of various vasoactive mediators, including eicosanoids $(4,20$, $21)$. This depressor effect of early steroid therapy is also confirmed in our experimental models of meconium aspiration

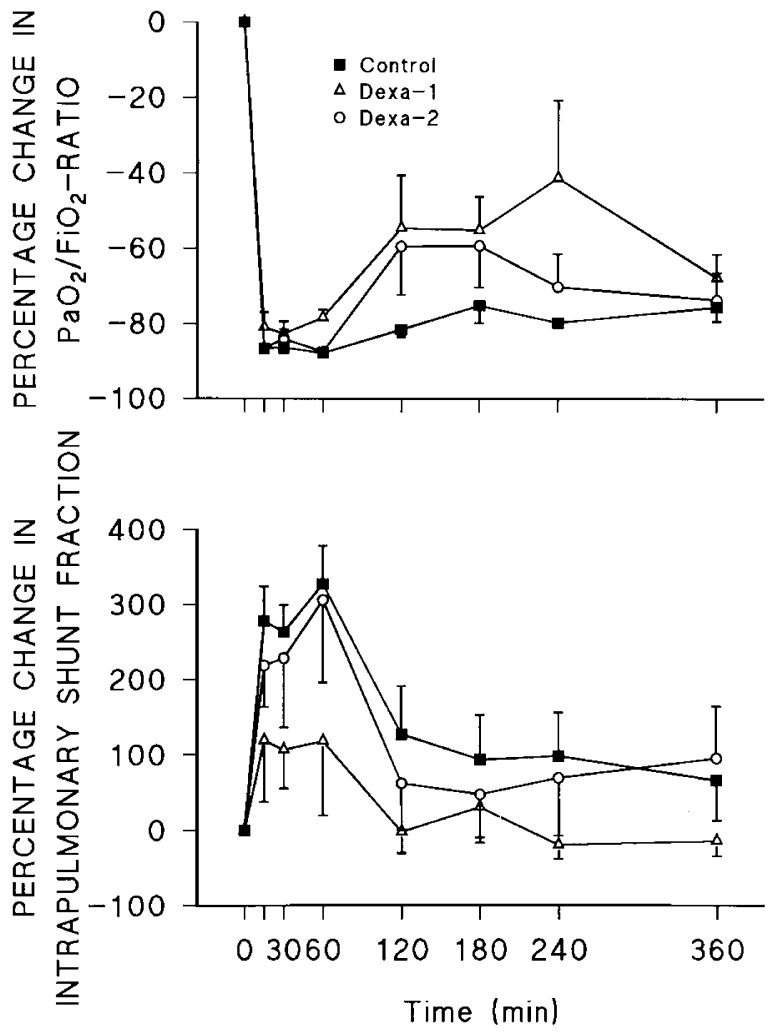

Figure 2. The percentage change in the ratio of $\mathrm{PaO}_{2}$ to fraction of inspired oxygen $\left(\mathrm{FiO}_{2}\right)$ (upper panel), and fraction of intrapulmonary shunting (lower panel) in 20 newborn piglets at baseline (0) and during $6 \mathrm{~h}$ after intratracheal instillation of meconium. Fourteen piglets were treated with dexamethasone given as a single i.v. dose $(0.5 \mathrm{mg} / \mathrm{kg})$ in two treatment schedules, either $1 \mathrm{~h}$ before (Dexa-1, $n=6$ ) or $1 \mathrm{~h}$ after meconium instillation (Dexa-2, $n=8$ ). Six nontreated piglets served as controls. Mean (SEM). 
Table 2. The ratio of $\mathrm{PO}_{2}$ to $\mathrm{FiO}_{2}$, and fraction of intrapulmonary shunting during 6 h after intratracheal instillation of meconium in control $(N=6)$, dexamethasone-pretreated (Dexa-1, $N=6)$, and dexamethasone-treated (Dexa-2, $N=8)$ neonatal piglets

\begin{tabular}{|c|c|c|c|c|c|c|c|c|}
\hline & \multicolumn{8}{|c|}{ Time $(\min )$} \\
\hline & 0 & 15 & 30 & 60 & 120 & 180 & 240 & 360 \\
\hline \multicolumn{9}{|l|}{$\mathrm{PO}_{2} / \mathrm{FiO}_{2}$} \\
\hline Dexa-1 & $70.0(11.5)$ & $14.3(8.8)$ & $12.3(3.9)^{*}$ & $15.9(3.8)^{* \dagger}$ & $33.2(25.8)$ & $32.7(14.8)^{*}$ & $41.3(30.5)$ & $23.3(9.5)$ \\
\hline Dexa-2 & $65.7(5.7)$ & $8.8(1.5)$ & $10.6(5.5)$ & $8.1(2.1)$ & $26.1(20.7)$ & $26.0(16.9)$ & $18.9(12.7)$ & $16.5(10.6)$ \\
\hline \multicolumn{9}{|c|}{ Shunt fraction } \\
\hline Control & $0.08(0.01)$ & $0.31(0.08)$ & $0.30(0.08)$ & $0.35(0.08)$ & $0.18(0.11)$ & $0.15(0.09)$ & $0.15(0.08)$ & $0.13(0.08)$ \\
\hline Dexa-2 & $0.11(0.06)$ & $0.33(0.12)$ & $0.33(0.21)$ & $0.42(0.30)$ & $0.16(0.15)$ & $0.14(0.14)$ & $0.16(0.19)$ & $0.19(0.17)$ \\
\hline
\end{tabular}

Results are expressed as the mean (SD).

$* p<0.05$ vs control.

$\dagger p<0.05$ vs Dexa-2.

Table 3. Lung tissue wet/dry-ratio, injury score, and PLA 2 activity $(U / L) 6 \mathrm{~h}$ after meconium instillation in control $(N=6)$, dexamethasone-pretreated (Dexa-1,N=6), and dexamethasone-treated (Dexa-2, $N=8$ ) neonatal piglets. Three piglets, ventilated for $6 \mathrm{~h}$, received dexamethasone but no material intratracheally (Dexa-3)

\begin{tabular}{cccc}
\hline & Wet/dry-ratio & Injury score & PLA $_{2}$ activity \\
\hline Control & $6.6(2.4)$ & $7.3(2.4)$ & $0.16(0.07)$ \\
Dexa-1 & $6.3(0.2)$ & $4.7(2.4)^{* \dagger}$ & $0.15(0.12)$ \\
Dexa-2 & $6.3(0.6)$ & $8.0(1.9)$ & $0.23(0.14)$ \\
Dexa-3 & $5.8(0.1)$ & $0(0)$ & $0.02(0.01)$ \\
\hline
\end{tabular}

Results are expressed as the mean (SD).

$* p=0.058$ vs controls.

$\dagger p<0.02$ vs Dexa-2.

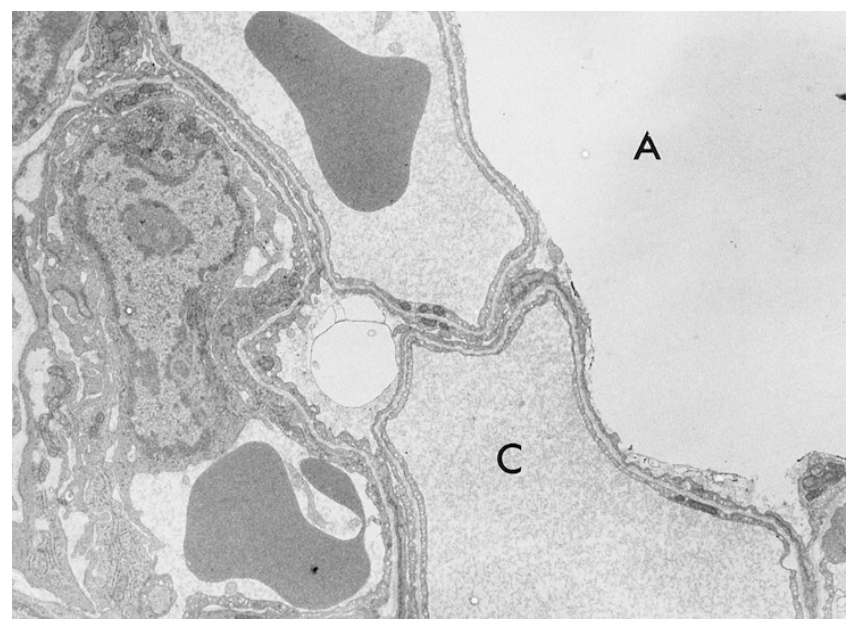

Figure 3. Normal looking alveolar capillaries after intratracheal meconium administration and prophylactic dexamethasone treatment (Dexa-1). $A$, alveolar space; $C$, capillary lumen. (Electron microscopy, $\times 9700$ ).

in neonatal and juvenile lungs (10). The simultaneous tendency to improved gas exchange after glucocorticoid administration, documented in the present study, may be due to its permissive effects on local hypoxic vasoconstriction resulting in redistribution of the pulmonary blood flow to the better ventilated areas (4). Further, reduction of pulmonary edema formation through diminished endothelial damage and vascular permeability, supported by a fall in pulmonary microvascular pressures, may also play a role $(10,18,21)$.

Several lines of evidence suggest that inflammation with intrapulmonary accumulation of neutrophils is intimately in-

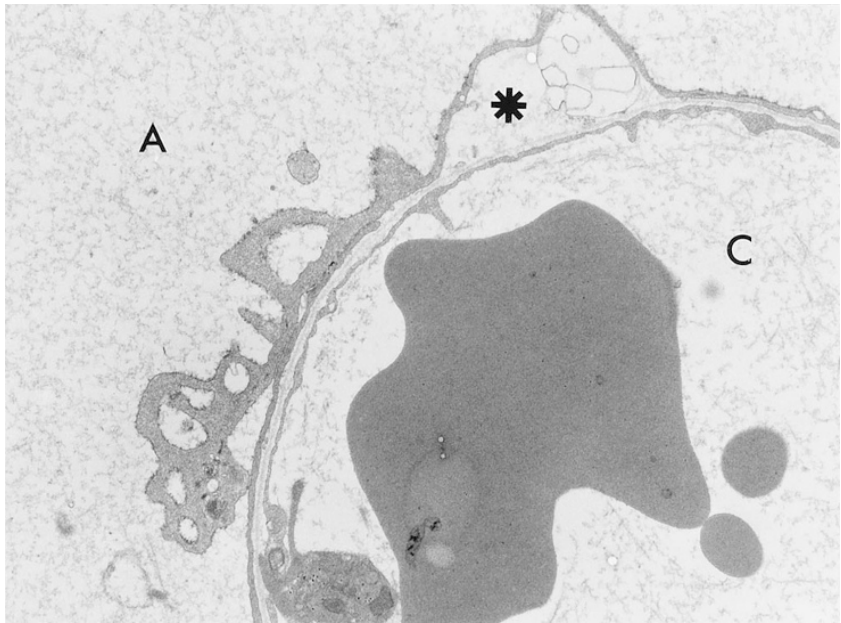

Figure 4. Meconium-instilled lungs with dexamethasone administration at $1 \mathrm{~h}$ after the insult (Dexa-2). The pulmonary vascular wall is intact, but the alveolar epithelium is detached $(*)$ and endoplasmic reticulum dilated. $A$, alveolar space; $C$, capillary lumen. (Electron microscopy, $\times 12,000$ ).

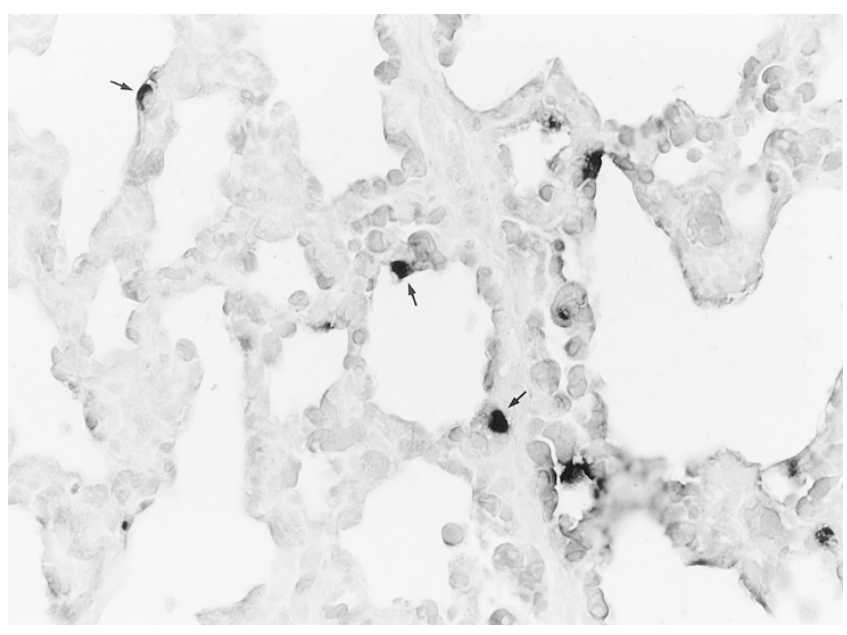

Figure 5. Dark staining apoptotic bodies (arrows) in alveolar walls in a meconium-instilled lung with prophylactic dexamethasone treatment (Dexa-1). (TUNEL, $\times 360$ ).

volved in the pathogenesis of acute injury in meconiumexposed lungs (1-3). The mechanisms that initiate the intense pulmonary inflammation a few hours after aspiration of meconium are complex and still poorly identified. Aspirated meco- 


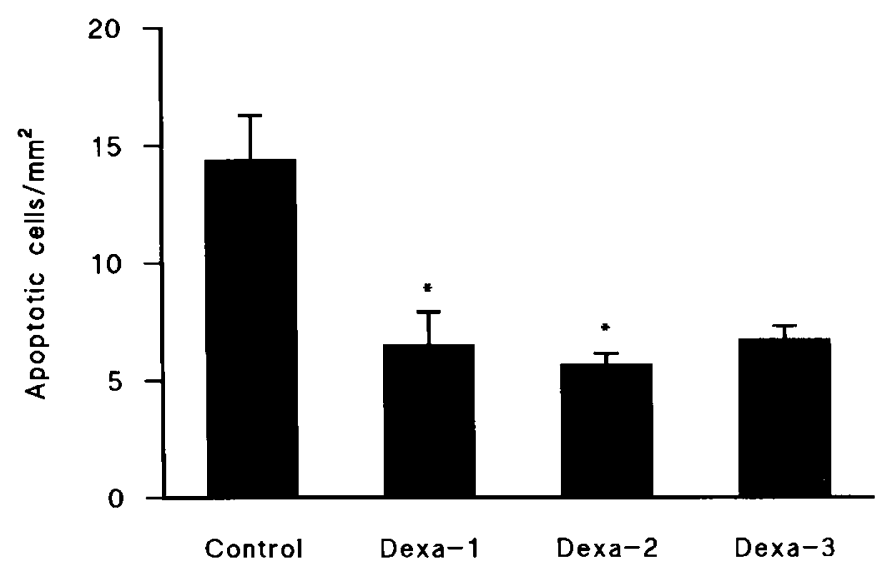

Figure 6. The number of apoptotic cells (per millimeter squared) in lung tissue of 20 newborn piglets $6 \mathrm{~h}$ after intratracheal instillation of meconium. Fourteen piglets were treated with dexamethasone given as a single i.v. dose $(0.5 \mathrm{mg} / \mathrm{kg})$ in two treatment schedules, either $1 \mathrm{~h}$ before (Dexa-1, $n=6)$ or $1 \mathrm{~h}$ after meconium instillation (Dexa-2, $n=8$ ). Six nontreated piglets served as controls. Three piglets were given dexamethasone but received no meconium intratracheally (Dexa-3). Mean (SEM). ${ }^{*} p<0.05$ vs controls.

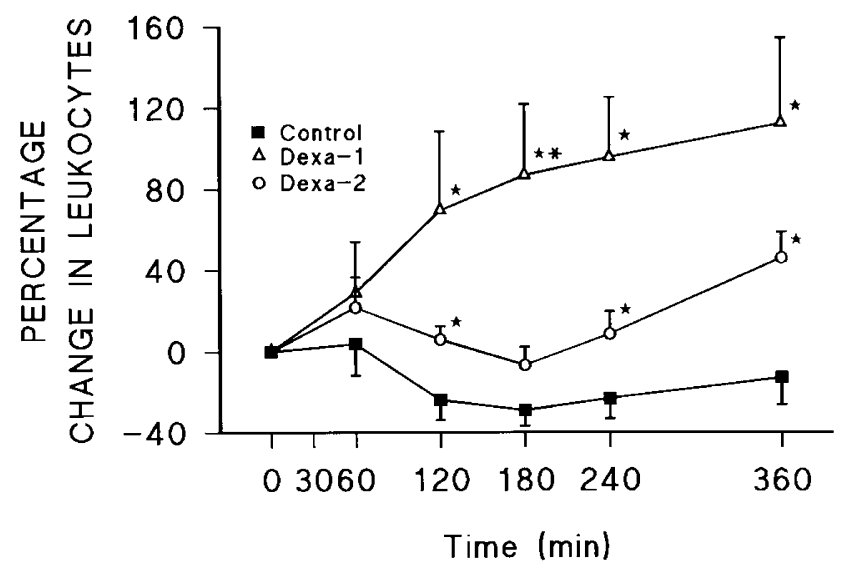

Figure 7. Percentage change in blood leukocytes in 20 newborn piglets at baseline (0) and during $6 \mathrm{~h}$ after intratracheal instillation of meconium. Fourteen piglets were treated with dexamethasone given as a single i.v. dose $(0.5 \mathrm{mg} / \mathrm{kg})$ in two treatment schedules, either $1 \mathrm{~h}$ before (Dexa-1, $n=6)$ or $1 \mathrm{~h}$ after meconium instillation (Dexa-2, $n=8$ ). Six nontreated piglets served as controls. Mean (SEM). ${ }^{*} p<0.05$ vs controls. ${ }^{*} p<<0.05$ vs Dexa-2.

nium may activate lung inflammatory cells to produce cytokines $(22,23)$, known to promote activation and synthesis of cellular phospholipase $\mathrm{A}_{2}$ and thereby stimulate the arachidonic acid release and generation of proinflammatory eicosanoids in the lungs $(24,25)$. The principal anti-inflammatory action of corticosteroids is suggested to be in their ability to inhibit induced phospholipase $A_{2}$ synthesis $(24,25)$. However, even though prophylactic dexamethasone administration tended to attenuate the inflammatory reaction in the meconiumexposed piglet lungs in the present study, this treatment did not reduce the lung $\mathrm{PLA}_{2}$ activity. On the other hand, we have previously demonstrated that intrapulmonary aspirated meconium challenges the lungs with high fetal pancreatic $\mathrm{PLA}_{2}$ activity and may thereby contribute to the pulmonary inflammatory response in meconium aspiration syndrome (15). Furthermore, early glucocorticoid treatment can affect many other steps in the inflammatory reaction, such as interruption of the cytokine cascade and inhibition of chemotactic factors resulting in reduction of neutrophil margination and influx into the lungs with simultaneous increase of the blood leukocyte count $(4,21,24)$.

Experimental meconium aspiration induces an early epithelial and endothelial ultrastructural injury in neonatal lungs, supposed to result from the intense inflammatory reaction in the lung tissue and/or the direct toxic injury to the airway epithelium $(3,15,26)$. These early structural alterations in the pulmonary epithelium are mainly found in the type I alveolar epithelial cells with much less severe change in other lung cells, commonly found also in acute damage of adult lungs from a variety of inhaled and blood-borne toxins $(18,27,28)$. Glucocorticoids may prevent alveolocapillary injury and loss of organ function by stabilizing cell and lysosomal membranes, especially when given early before extensive organ damage is reached $(18,28)$, as also evident from the present results. On the other hand, the high $\mathrm{PLA}_{2}$ activity in aspirated meconium could, through a direct effect on cell membranes or indirectly by production of cytotoxic lipid compounds, mediate the described ultrastructural changes in the piglet lungs $(27,28)$. Very early administration of glucocorticoids could, by inhibiting the $\mathrm{PLA}_{2}$ action, therefore lead to improved resistance to lung injury (4).

Apoptosis is a programmed cell death that does not result in inflammatory tissue injury, but rather is regarded as a cell clearance mechanism promoting resolution of inflammation (29). Nevertheless, there is some evidence to suggest that apoptosis may also play a role in acute lung injury. The mechanisms of the meconium aspiration-induced pulmonary cellular apoptosis remains undetermined, but may be associated with intrapulmonary production of cytokines, as is demonstrated to occur in septic lung injury $(23,30)$. Experimental administration of dexamethasone has been demonstrated to inhibit apoptotic cell death in unstimulated mammary epithelium and cytokine-induced lung epithelium $(31,32)$, thus corroborating our present results. Although the clinical relevance of our finding is unclear, glucocorticoids may act as survival factors in meconium-exposed lungs, probably through prevention of stimulated programmed cell death $(23,32)$.

In conclusion, the present results show that dexamethasone pretreatment has beneficial effects on oxygenation and pulmonary hemodynamics after neonatal meconium aspiration. This treatment further protects the lungs against the meconiuminduced ultrastructural changes and, together with the early administration, epithelial cell apoptosis. Our data thus suggest that evaluation of the beneficial effects of dexamethasone treatment in infants with severe meconium aspiration may be warranted. Further studies on the possible prophylactic use of steroids in deliveries with heavily stained amniotic fluid are still needed.

\section{REFERENCES}

1. Wiswell TE, Bent RC 1993 Meconium staining and the meconium aspiration syndrome. Pediatr Clin North Am 40:955-981

2. Tyler DC, Murphy J, Cheney FW 1978 Mechanical and chemical damage to lung tissue caused by meconium aspiration. Pediatrics 62:454-459

3. Davey AM, Becker JD, Davis JM 1993 Meconium aspiration syndrome: physiological and inflammatory changes in a newborn piglet model. Pediatr Pulmonol 16:101-108 
4. Morris HG 1985 Mechanisms of glucocorticoid action in pulmonary disease. Chest 88:133S-141S

5. Wang JY, Yeh TF, Lin YJ, Chen WY, Lin CH 1997 Early postnatal dexamethasone therapy may lessen lung inflammation in premature infants with respiratory distress syndrome on mechanical ventilation. Pediatr Pulmonol 23:193-197

6. Sanders RJ, Cox C, Phelps DL, Sinkin RA 1994 Two doses of early intravenous dexamethasone for the prevention of bronchopulmonary dysplasia in babies with respiratory distress syndrome. Pediatr Res $36: 122-128$

7. Davis JM, Whitin J 1992 Prophylactic effects of dexamethasone in lung injury caused by hyperoxia and hyperventilation. J Appl Physiol 72:1320-1325

8. Franz ID, Wang NS, Thach BT 1975 Experimental meconium aspiration: effects of glucocorticoid treatment. J Pediatr 86:438-441

9. Yeh TF, Srinivasan G, Harris V, Pildes RS 1977 Hydrocortisone therapy in meconium aspiration syndrome: a controlled study. J Pediatr 90:140-143

10. Soukka H, Halkola L, Aho H, Rautanen M, Kero P, Kääpä P 1997 Methylprednisolone attenuates the pulmonary hypertensive response in porcine meconium aspiration. Pediatr Res 42:145-150

11. Haworth SG, Hislop AA 1981 Adaptation of the pulmonary circulation to extrauterine life in the pig and its relevance to the human infant. Cardiovasc Res 15:108-119

12. Holopainen R, Soukka H, Halkola L, Kääpä P 1997 Meconium aspiration induces a concentration dependent pulmonary hypertensive response in newborn piglets. Pediatr Pulmonol 25:107-113

13. Laine VJO, Nyman KM, Peuravuori HJ, Henriksen K, Parvinen M, Nevalainen TJ 1996 Lipopolysaccharide induced apoptosis of rat pancreatic acinar cells. Gut 38:747-750

14. Schädlich HR, B 129 chler M, Beger HG 1987 Improved method for the determination of phospholipase $\mathrm{A}_{2}$ catalytic activity concentration in human serum and ascites. J Clin Chem Clin Biochem 25:505-509

15. Holopainen R, Aho H, Laine J, Peuravuori H, Soukka H, Kääpä P 1999 Human meconium has high phospholipase $\mathrm{A}_{2}$ activity and induces cellular injury and apoptosis in piglet lungs. Pediatr Res 46:626-632

16. Brigham KL, Bowers RE, McKeen CR 1981 Methylprednisolone prevention of increased lung vascular permeability following endotoxemia in sheep. J Clin Invest 67:1103-1110

17. Borg T, Gerdin B, Modig J 1985 Prophylactic and delayed treatment with high-dose methylprednisolone in a porcine model of early ARDS induced by endotoxaemia. Acta Anaesthesiol Scand 29:831-845

18. Smith LJ 1983 The effects of methylprednisolone on lung injury in mice. J Lab Clin Med 101:629-640
19. Perlman EJ, Moore GW, Hutchins GM 1989 The pulmonary vasculature in meconium aspiration. Hum Pathol 20:701-706

20. Vaage J 1985 Effects of high-dose corticosteroids on the pulmonary circulation. Acta Chir Scand Suppl 526:73-82

21. Olson NC, Brown TT, Anderson DL 1985 Dexamethasone and indomethacin modify endotoxin-induced respiratory failure in pigs. J Appl Physiol 58:274-284

22. Kojima T, Hattori K, Fujiwara T, Sasai-Takedatsu M, Kobayashi Y 1994 Meconiuminduced lung injury mediated by activation of alveolar macrophages. Life Sci 54:1559-1562

23. Jones CA, Cayabyab RG, Kwong KYC, Stotts C, Wong B, Hamdan H, Minoo P, DeLemos RA 1996 Undetectable interleukin (IL)-10 and persistent IL-8 expression early in hyaline membrane disease: a possible developmental basis for the predisposition to chronic lung inflammation in preterm newborns. Pediatr Res 39:966-975

24. Newton R, Kuitert LM, Slater DM, Adcock IM, Barnes PJ 1997 Cytokine induction of cytosolic phopholipase $\mathrm{A}_{2}$ and cyclooxygenase-2 mRNA is suppressed by glucocorticoids in human epithelial cells. Life Sci 60:67-78

25. Hoeck WG, Ramesha CS, Chang DJ, Fan N, Heller RA 1993 Cytoplasmic phopholipase $\mathrm{A}_{2}$ activity and gene expression are simulated by tumor necrosis factor: dexamethasone blocks the induced synthesis. Proc Natl Acad Sci U S A 90:44754479

26. Oelberg DG, Downey SA, Flynn MM 1990 Bile salt-induced intracellular $\mathrm{Ca}^{++}$ accumulation in type II pneumocytes. Lung 168:297-308

27. Niewoehner DE, Rice K, Duane P, Sinha AA, Gebhard R, Wangensteen D 1989 Induction of alveolar epithelial injury by phospholipase $A_{2}$. J Appl Physiol 66:261267

28. Durham SK, Selig WM 1990 Phospholipase $A_{2}$-induced pathophysiologic changes in the guinea pig lung. Am J Pathol 136:1283-1291

29. Savill J 1994 Apoptosis in disease. Eur J Clin Invest 24:715-723

30. Haimovitz-Friedman A, Cordon-Cardo C, Bayoumy S, Garzotto M, McLoughlin M, Gallily R, Edwards CK, Schuchman EH, Fuks Z, Kolesnick R 1997 Lipopolysaccharide induces disseminated endothelial apoptosis requiring ceramide generation. J Exp Med 186:1831-1841

31. Feng Z, Marti A, Jehn B, Altermatt HJ, Chicaiza G, Jaggi R 1995 Glucocorticoid and progesterone inhibit involution and programmed cell death in the mouse mammary gland. J Cell Biol 131:1095-1103

32. Wen L-P, Madani K, Fahrni JA, Duncan SR, Rosen GD 1997 Dexamethasone inhibits lung epithelial cell apoptosis induced by IFN- $\gamma$ and Fas. Am J Physiol 273:L921L929 